\title{
Las ventanas indiscretas de Michael Wolf, una mirada a la ciudad a través del ojo de la casa
}

\author{
MAFALDA RIVEIRO GOZÁLVEZ \\ Arquitecta. Doctoranda Departamento de Ideación Arquitectónica. ETSAM \\ Universidad Politécnica de Madrid \\ mafalda_riveiro@hotmail.com
}

\section{Resumen}

Desde muy temprano empecé a sospechar que esa tarea que tan importante parece, como es el "conócete a ti mismo", es una simple artimaña de una camarilla de sacerdotes, que no intentan sino engañar al hombre para que se aleje de toda actividad en el mundo exterior que le circunda, distraerle mediante exigencias imposibles de cumplir; se han propuesto arrastrarlo a una falsa contemplación interior. El hombre solamente llega a conocerse en cuanto conoce el mundo, ese mundo que solamente llegará a conocer en sí mismo, tal como solamente llegará a conocerse a sí mismo en él. Goethe (Sennett, 1991: 9)

El primer pensamiento que surge al observar las imágenes de Michael Wolf es que en ellas la ciudad aparece como extensión de nuestro propio espacio vital; lo que vemos a través de las ventanas forma parte de nuestro propio entorno vivido. De inmediato nos sentimos como ciudadanos inmersos en ese constructo urbano determinado.

¿Pero cómo es la ciudad que vemos en estas imágenes? En un principio podría parecer una ciudad escenario, ciudad de cartón pluma, liviana, donde la ligereza del muro cortina se hace protagonista: marco y cristal, frente a piedra y ladrillo. Idea que es reforzada por el punto de vista elegido por el artista; Wolf fotografía una ciudad desenraizada, en la que no existe la calle, ciudad Gotam desde las alturas, donde los edificios aparecen como despojados de su propia materialidad, sin gravedad, sin peso. Sin embargo, las imágenes de Wolf están pobladas de rastros de los seres que habitan la ciudad. Almas que asoman a través de las ventanas narrándonos sus historias y acontecimientos, su devenir en la cotidianidad de su guarida, reducto último de su intimidad. Imágenes de ciudad habitada, y por tanto ciudad. Imágenes en las que fluye la información sobre la vida de los otros. Miles de pantallas para ver el mundo, los ojos de la casa como una pantalla más.

Palabras clave: Michael Wolf; imágenes; ciudad; espacio vital; ventanas; rastros. 


\title{
The windows prying Michael Wolf, a look at the city through the eye of the house
}

\begin{abstract}
Early on, I started suspecting that this apparently so important task as it is to"get to know yourself" is a simple ploy made by a clique of priests, who only try to deceive man, so as to keep him away from all activity in the outerworld surrounding him, by distracting him with exigencies imposible to achieve; they intend to drag him into a fake self-contemplation. Man only gets to know himself as long as he knows the world, the world he will only get to know in itself, just as he will only get to know himself in it. Goethe (Sennett, 1991:9)
\end{abstract}

The first thought that emerges when staring at Michael Wolf's images, is that the city appears like an extension of our own living space. What we see through the windows belongs to our own living environment. We feel like citizens immersed in that particular urban construct at once.

But, what does the city we see in these images look like? At first, it could look as a setting city, foam board city, light, where curtain wall lightness turns out to be principal, frame and glass versus Stone and brick. Idea that is reinforced by the point of view chosen by the artist; Wolf takes pictures of an unrooted city, where there are no streets, Gotham city from the hights, where buildings have been stripped of their own massiveness, without gravity, without weight. Despite this, Wolf's images are overwhelmed with traces of beings inhabiting the city. Souls leaning out the windows telling us their stories and affairs, their outcoming in the everyday life of their shelter, ultimate bastion of their intimacy. Images of an inhabited city, and therefore a city. Images with flowing information about the life of the others. Thousands of screens to watch the world, the eye of the house as one screen more.

Key words: Michael Wolf, images, city, living space, windows, traces.

Michael Wolf es un fotógrafo de origen alemán nacido en Munich en 1954, educado en Estados Unidos y Canadá. Estudió en la Universidad de Berckeley, y posteriormente en Essen, Alemania, bajo la tutela del famoso fotógrafo alemán Otto Steinert. Comenzó su carrera como reportero gráfico en el año 1994, trabajando para la revista alemana Stern en Hong Kong, puesto que desempeñó durante ocho años. En el año 2001, todavía residiendo en China, comienza su carrera artística en solitario, desarrollando desde entonces sus propios proyectos personales. 
Los temas principales de su obra giran en torno a la ciudad, lo vernáculo y la identidad cultural, siempre enfocados desde dentro del entorno urbano. Muestra de ello son sus series: Architecture of Density, en la que fotografía los grandes rascacielos de la ciudad de Hong Kong, y que comparte rasgos comunes con la serie que nos ocupa, alejándose a su vez de la misma, en gran parte debido a las diferencias culturales entre el entorno asiático y americano de ambos proyectos; o $100 \times 100$, en la que fotografía el interior de 100 habitaciones del edificio de protección pública más antiguo de Hong Kong, justo antes de ser demolido, en el que cada residente tiene una habitación de unos 100 pies de superficie $\left(9,3 \mathrm{~m}^{2}\right)$.

En el año 2007, el Museo de Fotografía Contemporánea de Chicago, junto con el U.S. Equities Realty Artist in Residence Program, invitaron a Wolf a fotografiar el paisaje urbano de Chicago. El resultado de aquel encargo es la serie en que se basa este ensayo: The Transparent City.

El primer pensamiento que surge al observar las imágenes de Michael Wolf es que en ellas la ciudad aparece como extensión de nuestro propio espacio vital; lo que vemos a través de las ventanas forma parte de nuestro propio entorno vivido. De inmediato nos sentimos como ciudadanos inmersos en ese constructo urbano determinado, que es la ciudad de Chicago, o más concretamente en la zona de la ciudad denominada The Loop, distrito financiero del centro en el que conviven grandes edificios de oficinas y bloques residenciales. Este barrio ha sido durante años el lugar de experimentación e innovación arquitectónicas de la ciudad, donde se encuentran importantes edificios como las Sears Towers. Se trata, por tanto, de un barrio con una actividad intensa, también en lo relativo a lo cultural y comercial.

¿Pero cómo es la ciudad que vemos en estas imágenes? Es una ciudad de edificaciones en altura, casi todas ellas de un tipo arquitectónico determinado: rascacielos con estructura metálica y muro cortina, es decir, la superficie acristalada se maximiza, convirtiéndose el hueco y por tanto el vidrio en el protagonista de las imágenes. Este tipo de ciudad es, todavía hoy, rápidamente asimilada por el colectivo ciudadano occidental como una ciudad moderna, a pesar de que la plena implantación de este tipo arquitectónico en Norteamérica tuvo lugar en la década de los 50 del siglo pasado, y su existencia se vaticinó con años de antelación. Ya en 1914 el ingeniero Paul Scheerbart argumentaba: 
Habitamos mayoritariamente en espacios cerrados que conforman el medio donde se desarrolla nuestra cultura... Si deseamos trascender nuestra cultura a un plano superior, tenemos que cambiar por completo nuestra arquitectura. Y ello solamente será posible cuando suprimamos la sensación de cerramiento de los espacios en que vivimos. Y esto solamente será viable mediante la introducción de la Arquitectura del Cristal. (Sennett, 1991: p.136)

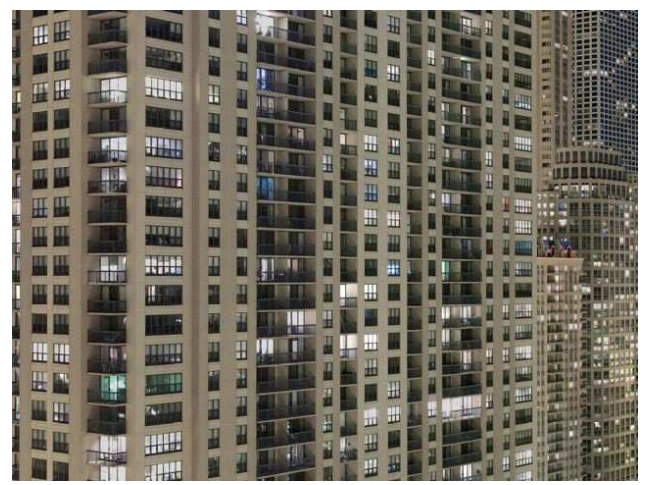

Fig.1. Transparent city $\mathrm{n} \mathbf{0} 80$. Fuente: Michael Wolf, www.photomichaelwolf.com/transparent_city/tc80.jpg

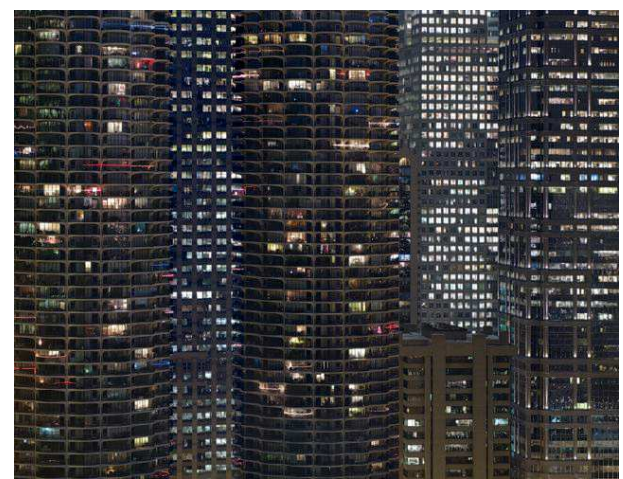

Fig. 2. Transparent city $\mathrm{n}^{\mathrm{o}} 62$. Fuente: Michael Wolf, photo-michaelwolf.com/-transparent-city/17

Es una ciudad muestrario de la "moderna sensación de apertura y amplitud protegidas", que según describe Sennett se caracteriza por la total aprehensión del exterior desde el interior, pero sin sentir el frío, ni el viento, ni la humedad. Es decir, las paredes de cristal garantizan la visibilidad plena, sin que el resto de los sentidos queden expuestos. El predominio de lo visual dentro de la casa moderna se acompaña de la sensación de aislamiento.

Es una ciudad densa, por cuanto no aparece el aire entre edificios, sino que éstos se superponen como si de un telón de fondo tras otro se tratara; se aplanan; se abstraen. Las vistas están intencionadamente escogidas para que todo sea lleno; hecho construido. Por ello, el artista enfoca la cámara hacia las plantas intermedias de los edificios, donde la forma es constante, ó a las esquinas, de manera que ambas fachadas se convierten en un plano continuo. Es una ciudad hiperpoblada, en la que apreciamos la colmatación del tejido urbano, la megalópolis. 
Ciudad desenraizada, en la que no existe la calle y la arquitectura se desmaterializa. Sin la fuerza de la gravedad no hay peso, ciudad ligera e ingrávida, de nuevo una abstracción de la ciudad. Al perder de vista la calle perdemos toda referencia al anclaje de la ciudad, a su parte más terrenal. El nivel de los acontecimientos que constituye la calle, que es inherente y generadora de la realidad de cualquier ciudad, aquí se nos oculta.

Ciudad infinita, puesto que los edificios no tienen fin; Wolf nunca mira hacia arriba, ocultándonos la verdadera dimensión vertical de los edificios que fotografía, ocultándonos el aire y el cielo de la ciudad. De nuevo cualquier vestigio de la naturaleza (el sol, la luna y las estrellas) e incluso la metáfora de alcanzar cualquiera de ellos desde las alturas, son anulados de las imágenes.

Y cuando mira hacia abajo, lo hace alejando el objetivo; convirtiendo la ciudad en maqueta. Aparece por primera vez el volumen edificado, pero en miniatura, como una ciudad lego, convertida en juego y por tanto irreal.

En algunas fotografías el artista se acerca a un único edificio, cuya retícula constructiva ocupa, entonces, la totalidad de la imagen. La ciudad en este caso, se ve reducida a un entramado estructural inconcluso, vertical y horizontal, conformando los huecos. Las ventanas se insertan como las teselas de un mosaico, formando un patrón que podría repetirse hasta el infinito, puesto que no sólo han desaparecido el suelo y el cielo, sino también los límites laterales del edificio, que ya sin ninguna arista vista, es un plano, en el que desaparece también el eje vertical anteriormente predominante.

Incluso en las imágenes que contienen varios edificios, en los que algunos de ellos son de mayor antigüedad y por tanto muestran una arquitectura más masiva, más piedra y ladrillo, los elementos constructivos que más se diferencian según la época de construcción, basamento y coronación, se omiten, no distraen la imagen.

Mediante todas estas operaciones la ciudad se abstrae, pero también se homogeniza, tiene lugar una pérdida de identidad y diferenciación de un edificio sobre otro, de una imagen sobre las demás. Vemos la ciudad globalizada y alienante. Aparece ante nosotros la ciudad microchip, de la que nos habla Toyo Ito (2000: 136) en su libro Escritos, una ciudad que emerge al hacer desaparecer el lado real del espacio urbano, su sustancia, y que comparte con el microchip los 
siguientes atributos: fluidez; multiplicidad de capas y fenomenalidad. Un espacio urbano constituido por objetos inmóviles, como la arquitectura y las obras de ingeniería civil, y por la acumulación de diversos flujos: de actividad, de las personas, de los coches, de energía o de información.

El artista de The Transparent City nos muestra una ciudad relatada en capas, vanagloriando la esencia construida por un lado, pero al mismo tiempo diseccionando la ciudad, disgregándola en distintos niveles de conocimiento por acción o por omisión. Y es probablemente mediante la omisión, que llegamos a aprehender los rasgos más destacables de la ciudad moderna, la ciudad de hoy, que nos muestra Michael Wolf.

La abstracción y la homogeneización se conforman como tabula rasa sobre la que se asienta lo que no hay o lo que no se ve en estas imágenes; esa suerte de telépolis, (Echeverría, 1999) en la que las formas clásicas de organización social, basadas en la territorialidad, carecen de sentido, y donde la estructura topológica básica no es el recinto con interior, frontera y exterior, sino la red de interconexiones que vincula puntos geográficamente dispersos pero unidos por la tecnología. Una nueva ciudad superpuesta a la ciudad tradicional, un conjunto de formas de interacción social, que se asumen como ciudad o forma de vida pese a su inmaterialidad.

Muchas de las imágenes están realizas al anochecer, o al amanecer, cuando la iluminación artificial que inunda las estancias, hace que de éstas resuene su contenido.

La iluminación de los interiores diáfanos, los interiores en contraluz, como si del panóptico de Bentham ${ }^{1}$ se tratara, nos sitúan en un enclave privilegiado, controlando visualmente el espacio, la mirada como símbolo de poder y control sobre lo que vemos (Ubeda, 2006).

\footnotetext{
${ }^{1}$ Proyecto de edificio para prisión diseñado por Jeremy Bentham, a finales del s. XVIII. Se trata de un edifico de planta circular, en cuyo perímetro se distribuyen las celdas, iluminadas. En el centro de la planta se ubica una torre de vigilancia, desde la que se controla visualmente, sin ser visto, todo el espacio circundante. Esta distribución espacial responde a la metáfora del ojo que todo lo ve (pan-óptico, ver-todo, en griego), que tiene sentido como representación de los conceptos de vigilancia y castigo heredados del pensamiento ilustrado.
} 
Fig. 3.

Transparent city $\mathrm{n}^{\mathrm{0}} 43$.

Fuente: Michael Wolf

photo-michaelwolf.com/-

transparent-city/13

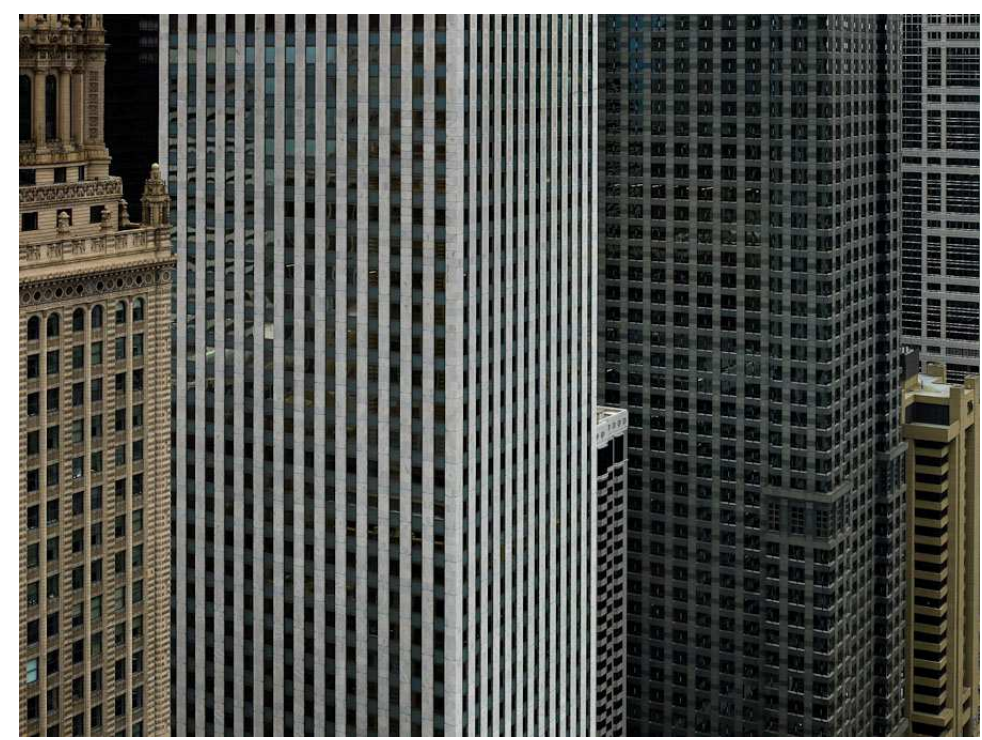

Las imágenes están pobladas de rastros de los seres que habitan la ciudad. Almas que asoman a través de las ventanas narrándonos sus historias y acontecimientos, su devenir en la cotidianidad de su guarida, y también el frenesí en las últimas horas del día en la oficina, en una oda particular a la actividad de la metrópoli.

En las imágenes podemos observar reuniones de última hora; despachos atestados de papeles tras una ardua jornada de trabajo; los últimos y solitarios empleados que permanecen en una oficina casi desierta; o el directivo que estira el cuerpo en la intimidad de su despacho antes de irse a casa. Pero también observamos la casa; la hora de las noticias frente al televisor; un único individuo solitario que sigue trabajando frente al ordenador, prolongando el espacio de la oficina hasta su intimidad; un recién llegado del despacho, que aún con el traje puesto se prepara la cena.

Imágenes de ciudadanos solitarios con una conducta tan homogénea como su propio espacio urbano. De nuevo, parafraseando a Toyo Ito, individuos pertenecientes a una sociedad homogeneizada, como cubierta de una gran película de plástico transparente, viviendo una vida simulada y ficticia.

El propio Wolf, en una entrevista realizada por Geoff Manaugh, relata que lo que más le sorprendió fue ver lo aburrida que era la vida cotidiana de la 
gente. Puesto que todo lo que veía era gente sentada frente al ordenador, o gente cenando frente al televisor, y mucha gente sola ${ }^{2}$. Gente, de entre veinticinco y cuarenta años, que llegaba a casa cansada de trabajar. Y puesto que no estoy sólo (del todo), estoy en la ciudad...

Así pues, toda arquitectura es ciertamente, una arquitectura del interior, o, mejor aún, desde el interior; las persianas que filtran la luz del sol o la línea del agua constituyen, en el interior, otra fachada, junto al color y a la forma de los cuerpos que, tras la persiana, viven, duermen, se aman (...) (Rossi, 1998: p.37)

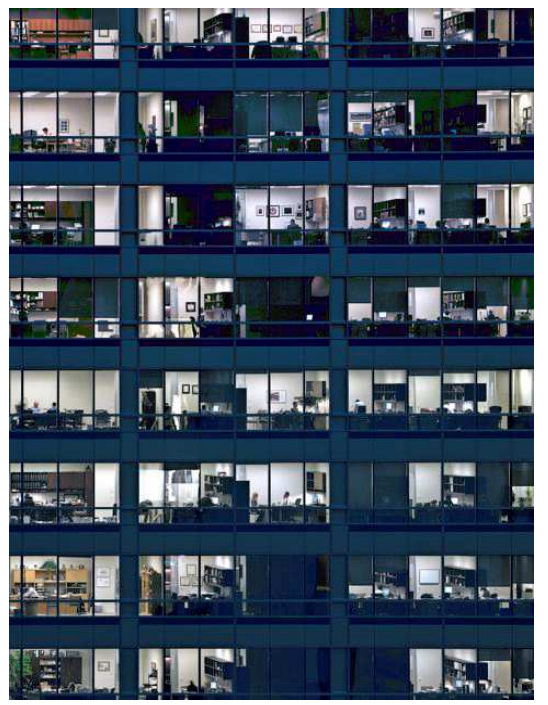

Fig. 4. Transparent city no 57.

Fuente: Michael Wolf,

www.photomichaelwolf.com/transparent_city/tc57.jpg

Sin embargo, Wolf va un paso más allá...

Tras varios meses tomando estas fotografías, en la fase de posproducción Wolf descubre figuras humanas que le habían pasado inadvertidas al realizar las fotografías. Tras este hallazgo, se dispone a analizar todas las imágenes de la serie ampliándolas al máximo, en la búsqueda de cualquier rastro de presencia inédito.

${ }^{2}$ En diciembre de 2008 la serie The Transparent City, se expuso por primera vez en el Museo de Fotografía Contemporánea de Chicago, editándose a su vez el catálogo de la exposición con el mismo nombre. Geoff Manaugh fue el autor del prólogo de dicho libro. El folleto de la exposición se puede consultar en www.photomichaelwolf.com/...city/08-04-29_Aperture-Cover.pdf (30/10/12) 
Como resultado de esta búsqueda nos muestra una segunda capa de acontecimientos, que añade a la serie inicial de fotografías con el nombre Transparent City Details. En ésta, y a pesar de la pixelación de las imágenes, reconocemos individuos suspirando, leyendo, pensando, viendo la televisión con la mirada fija en la pantalla, hablando por teléfono, desnudándose o jugando al golf; y también, haciéndole un corte de mangas al voyeur de la ciudad, como respuesta al haber rebasado los límites de la privacidad de la guarida del hombre, reducto último de su intimidad. Y puesto que uno puede mirar la vida de los otros, los otros también pueden mirar la vida de uno.

Fig. 5. Transparent city details $\mathrm{n}^{\mathrm{o}} 07$. Fuente: Michael Wolf, http://photo-michaelwolf.com/ - transparent-city-details/7

Imágenes de ciudad habitada, y por tanto ciudad. Imágenes en las que fluye la información sobre la vida de los otros. Imágenes que contienen muchos más datos del ser en la ciudad de los que a priori pudiera parecer.

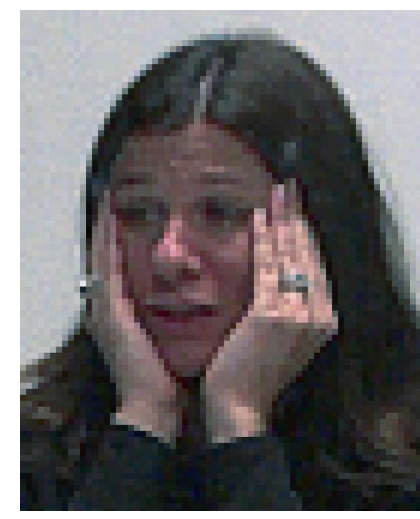

¿Pero cómo se relaciona este ser en la ciudad?

El hombre crea condiciones artificiales; eso es la arquitectura. El hombre repite, transforma y expande física y psíquicamente sus esferas físicas y psíquicas; crea "entornos" en su sentido más amplio. Utiliza los recursos necesarios para satisfacer sus necesidades y alcanza sus sueños; expande su cuerpo y su mente: se comunica. (Hollein, 2004: 12)

$\mathrm{Al}$ igual que la casa del hombre era artificial, en cuanto al predominio de lo visual, y la anulación por tanto del resto de los sentidos (tan artificial como es en parte ver un árbol inclinarse por la acción del viento sin escuchar el sonido de sus ramas, dice Sennett), también lo es, y cada vez más, la manera que tiene la gente de comunicarse entre sí.

Con los nuevos modos de comunicación, y fundamentalmente desde la aparición de internet 2.0, y las redes sociales, la casa o la plaza han dejado de ser un espacio físico de encuentro. 
Las comunicaciones se establecen ahora de manera unipersonal, mediante una identidad simbólica o real y a través de la pantalla del ordenador. Desde mi refugio y con el anonimato de la red de redes, que a partir de ahora es el mundo real. Al que accedo a mi libre albedrío, sin depender de nada ni de nadie, y durante el tiempo que quiero.

Aunque no lo veamos con nuestros ojos, nuestro cuerpo está constantemente en contacto con el aire de la tecnología, y lo sentimos, e incluso ese aire conforma el ritmo de nuestros cuerpos. Es que nosotros, sin darnos cuenta, hemos empezado a tener, día a día, un cuerpo transformado en androide. (Ito, 2000:100)

Miles de pantallas para ver el mundo, los ojos de la casa como una pantalla más.

\section{Bibliografía}

ECHEVERRÍA, Javier (1999): Los Señores del aire: Telépolis y el Tercer Entorno. Destino, Barcelona.

Hollein, Hans (2004): “Todo es arquitectura". Oeste no 17: Efectos Especiales. Colegio Oficial de Arquitectos de Extremadura, Cáceres, pág. 1-17.

ITO, Toyo (2000): Escritos. Colegio Oficial de Aparejadores y Arquitectos Técnicos de Murcia, Murcia.

RossI, Aldo (1998): Autobiografía científica. Gustavo Gili, Colección “GG Reprints", Barcelona.

SENNET, Richard (1991): La conciencia del ojo. Ediciones Versal, Barcelona.

ÚBEDA, María Elena (2006): La mirada desbordada: El espesor de la experiencia del sujeto estético en el marco de la crisis del régimen escópico. Editorial de la Universidad de Granada, Granada. 